Jochen Taupitz

\title{
15. Humane Hirnorganoide: Die deutsche Rechtslage
}

\subsection{Einleitung}

Hirnorganoide (zerebrale Organoide, „cerebroids“) ${ }^{1}$ sind außerhalb des Körpers aus Stammzellen kultivierte, dreidimensionle Zellverbände, die in Zelltypen, Aufbau und Funktion verschiedenen Gehirnbereichen ähneln. ${ }^{2}$ Spezielle Rechtsregeln zur Herstellung und Verwendung von Organoiden im Allgemeinen oder für Hirnorganoide im Besonderen existieren in Deutschland nicht. Deren juristische Einordnung hat wie diejenige anderer menschlicher Zellen, Gewebe und Organe mehrere Regelungsbereiche in den Blick zu nehmen: Zum einen geht es um die Herkunft bzw. um die Gewinnung des Ausgangsmaterials, sodann um die Einordnung der Organoide selbst und schließlich um die Art und Weise ihrer (geplanten) Verwendung.

Die Rechtslage zur Herstellung von Organoiden im Allgemeinen einschließlich der Gewinnung des Ausgangsmaterials sowie zur späteren Verwendung der Organoide hat der Verfasser ausführlich bereits an anderer Stelle dargestellt. ${ }^{3}$ Besonderheiten für Hirnorganoide ergeben sich insoweit nicht, sodass hier zusammengefasst nur Folgendes auszuführen ist: Bei Hirnorganoiden, die aus menschlichen Körperzellen über induzierte pluripotente Stammzellen kultiviert werden, ${ }^{4}$ stellt sich in zugespitzter Form die seit langem insbesondere im Zusammenhang mit Biobanken ${ }^{5}$ diskutierte Frage, wie spezifisch die Spender der Ausgangszellen (über ihre Einwilligung in die Entnahme der Zellen hinaus) ${ }^{6}$ über die spätere Verwendung informiert sein und darin einwilli-

1 So die Bezeichnung von Baertschi et al. (2020:3).

2 Zu Informationen über Organoide siehe Bartfeld et al. (2020) sowie Zenke/Bartfeld (Kap. 5).

3 Taupitz (2020a: 805 ff.); Taupitz (2020b: 212 ff.).

4 Sofern es sich um embryonale Stammzellen handelt, ist das Stammzellgesetz einschlägig.

5 Dazu hier statt vieler Deutscher Ethikrat (2010).

6 Dass für die Entnahme aus dem Körper eine Einwilligung erforderlich ist, ist selbstverständlich, siehe statt vieler Taupitz (2020a: 806 f.). 
gen müssen. ${ }^{7}$ Insoweit wird man sagen können, dass angesichts der besonderen - auch anthropologischen - Bedeutung, die dem menschlichen Gehirn beigemessen wird, die Spender wissen und ausdrücklich darin einwilligen müssen, dass ihre Zellen für die Kultivierung von Hirnstrukturen verwendet werden sollen. ${ }^{8}$ Sofern die Hirnorganoide später auf andere Menschen übertragen werden sollen, müssen die Spender der Ausgangszellen auch darin einwilligen ${ }^{9}$ und ist zudem für die Entnahme der Zellen das Transplantationsgesetz (TPG) anwendbar. ${ }^{10}$ (Hirn-)Organoide sind zudem Arzneimittel, wenn ihre spätere Verwendung eine therapeutische Zweckbestimmung hat („zur Heilung oder Linderung oder zur Verhütung [...] menschlicher Krankheiten oder krankhafter Beschwerden bestimmt", § 2 Abs. 1 Nr. 1 AMG). Dabei können sie insbesondere Arzneimittel für neuartige Therapien („Advanced Therapy Medicinal Products“, ATMP) sein. ${ }^{11}$ Die einschlägigen Vorschriften erfassen sowohl die Gewinnung der Ausgangszellen als auch die spätere Verwendung der (Hirn-)Organoide. ${ }^{12}$ Sofern (Hirn-)Organoide auf Tiere übertragen werden, ist das Tierschutzgesetz einschlägig; auch können die dadurch entstehenden Chimären ihrerseits möglicherweise einen besonderen moralischen und/oder rechtlichen Status aufweisen. ${ }^{13}$

Der nachfolgende Beitrag befasst sich schwerpunktmäßig mit dem rechtlichen Status der Hirnorganoide. Um den moralischen Status von „Mini-Gehirnen“"14 ist international bereits eine heftige Debatte entbrannt, allerdings nicht immer mit hinreichender Unterscheidung zwischen fiktionalen empiriefreien Gedankenexperimenten (,philosophischen Zombies") ${ }^{15}$ einerseits und wissenschaftsbasierter ethischer Folgenabschätzung andererseits. ${ }^{16} \mathrm{Da}$ „auf kaum einem Feld die Phantasie schneller ins Kraut

7 Speziell zu Hirnorganoiden: Boers et al. (2016: 939 f.); Farahany et al. (2018: 431 f.); Yeager (2018); Jácomo (2020: 7 f.); Koplin/Savulescu (2019: 760); Hyun et al. (2020: 2 f.); Schicktanz (2020: 198).

8 Taupitz (2020a: 807); Taupitz (2020b: 217) - Auf die Besonderheiten, wenn Zellen von Minderjährigen verwendet werden sollen, kann im Rahmen dieses Beitrags nicht eingegangen werden.

9 Schröder/Taupitz (1991: 70).

10 Taupitz (2020a: 808 f.); Taupitz (2020b: 217 ff.). - Für den Umgang mit ihnen und ihre gegebenenfalls später stattfindende Übertragung auf andere Menschen ist das TPG dagegen in der Regel nicht anwendbar, siehe Taupitz (2020a: 810 f.); Taupitz (2020b: 224 f.).

11 Taupitz (2020a: 811 f.); Taupitz (2020b: 225 ff.).

$12 \mathrm{Zu}$ den besonderen Problemen, die bezogen auf Unbedenklichkeit und Wirksamkeit in diesem $\mathrm{Zu}-$ sammenhang die ,personalisierte“ Medizin aufwirft, siehe Hyun et al. (2020: 3).

13 Taupitz/Weschka (2009); Deutscher Ethikrat (2011: 110 ff.); National Academies (2021: $67 \mathrm{ff}$.); Munsie et al. (2017: 944); Loike (2018); Chen et al. (2019: 462 ff.); Hyun et al. (2020: 4); Schicktanz (2020: 203 ff.).

14 Parsch (2019b); Viciano (2020); siehe auch Lavazza/Massimini (2018: 606): „brain in a vat“.

15 Bitar (2020). Zu philosophischen Zombies siehe Kirk (2009).

16 Kritisch Schicktanz (2020: 194 f.). Lavazza/Massimini (2018: 606) sprechen dagegen offen von einem Gedankenexperiment, das nun zum Laborexperiment werde. 
schießt als auf dem der Hirnforschung “17, werden sogar Frankenstein-Fantasien entwickelt; ${ }^{18}$ andere sprechen von der „Hexenküche der neuen Zauberlehrlinge“ ${ }^{19}$

\subsection{Verfassungsrechtliche Rahmenbedingungen}

Das deutsche Rechtssystem beruht auf einer Freiheitsvermutung, die in zahlreichen Grundrechten des Grundgesetzes (GG) zum Ausdruck kommt: Aus (verfassungs-)rechtlicher Sicht ist - im Unterschied zum häufig in der Ethik gewählten Ausgangspunkt nicht zu fragen, was der Mensch tun darf, sondern was der Staat verbieten darf. ${ }^{20}$ Dieser „freiheitliche“ Ausgangspunkt ist deshalb so wichtig, weil damit die Begründungslast verteilt ist: ${ }^{21}$ Nicht die Freiheit ist zu begründen, sondern das rechtliche Verbot oder die Einschränkung der Freiheit. Das gilt insbesondere auch für die in Art. 5 Abs. 3 GG garantierte Wissenschaftsfreiheit, die für die noch sehr weit am Anfang stehende Entwicklung von Hirnorganoiden von zentraler Bedeutung ist: Nicht die Ziele oder Wege der Wissenschaft bedürfen der argumentativen Legitimation, sondern ihre Unerlaubtheit, nicht die Wissenschaft hat ihr Tun oder Unterlassen zu rechtfertigen, sondern die Rechtsordnung hat zu begründen, warum das, was die Wissenschaft tut oder tun will bzw. nicht tut oder tun will, in concreto illegitim ist. Auch hat die Wissenschaft aus rechticher Sicht nicht etwa ihren Nutzen für die Gesellschaft oder den Einzelnen zu beweisen und obliegt der Wissenschaft auch keine argumentative Bringschuld gegenüber der Gesellschaft. Vielmehr hat der Grundgesetzgeber die Wissenschaft um ihrer selbst willen unter das Primat der Freiheit gestellt - und zwar ganz pragmatisch betrachtet deshalb, weil die Gesellschaft à la longue betrachtet damit besser fährt als mit jeder von noch so hehren Zielen getragenen A-priori-Beschränkung wissenschaftlichen Erkenntnisfortschritts. ${ }^{22}$ Im Ergebnis bedeutet das, dass jede Beschränkung der Wissenschaftsfreiheit einer tragfähigen Begründung bedarf, wobei das Ziel nur der Schutz anderer Güter mit Verfassungsrang sein kann. ${ }^{23}$

Neben der Wissenschaftsfreiheit sind bezogen auf die Herstellung und Verwendung von Hirnorganoiden weitere Grundrechte wie insbesondere das Allgemeine Persönlichkeitsrecht (Art. 2 Abs. 1 in Verbindung mit Art. 1 Abs. $1 \mathrm{GG}$ ) und das Recht auf Leben

17 Kuroczik (2018).

18 Kurlemann (2013); Goodall (2020).

19 Müller-Jung (2013).

20 Hufen (2001: 442).

21 Hierzu und zum Folgenden Taupitz (2002: 23 f.).

22 Vgl. BVerfGE 141, 143 (169); 90, 1 (11 ff.); 47, 327 (369 f.).

23 BVerfGE 141, 143 (169); 128, 1 (41); 12289 (107). 
und körperliche Unversehrtheit (Art. 2 Abs. 2 GG) zu nennen. Diese Grundrechte sind in erster Linie Abwehrrechte, hier vor allem der Spender der für die Hirnorganoide verwendeten Zellen. Aus ihnen folgt bezogen auf (zukünftige), von Hirnorganoiden gesundheitlich eventuell profitierende Patienten aber auch, dass der Staat nicht ohne hinreichenden Grund z. B. therapeutische Maßnahmen verbieten darf. Wie einleitend ausgeführt, soll diesen Fragen der Gewinnung des für die Hirnorganoide benötigten Ausgangsmaterials hier ebensowenig ausführlich nachgegangen werden wie den Fragen der späteren Verwendung der Organoide. Gleiches gilt für den Tierschutz, der als Rechtsprinzip in der Verfassung verankert ist (Art. 20a GG). Er kann sowohl für die Gewinnung des Ausgangsmaterials als auch für die Übertragung von Hirnorganoiden auf Tiere von Bedeutung sein.

Im Zentrum der Erörterung eines besonderen rechtlichen Status von Hirnorganoiden stehen zweifellos die Menschenwürde (Art. 1 Abs. $1 \mathrm{GG}$ ) und das Recht auf Leben und körperliche Unversehrtheit (Art. 2 Abs. 2 GG). Mit Blick auf Menschenwürde und Recht auf Leben wird in der internationalen Diskussion bereits erörtert, ob man Hirnorganoide einfach zerstören darf: „Würde die Zerstörung eines solchen Organismus Mord bedeuten?" 24

Da das menschliche zerebrale Organiod neuronale Aktivität zeigt und deshalb gemäß dem Hirntodkriterium, das auf Rechtssubjekte anwendbar ist, nicht tot ist, würde die Zerstörung möglichrweise eine Würdeverletzung und die Verletzung von Rechten - vor allem des Rechts auf Leben - eines Rechtssubjekts bedeuten. ${ }^{25}$

Auch bezogen auf die Herstellung von Hirnorganoiden für Forschungszwecke wird eine Würdeverletzung für möglich gehalten. ${ }^{26}$

24 Goodall (2020): „Would destroying such an organism be murder?“

25 Lavazza/Pizzetti (2020: 10): „Since the human cerebral organoid presents some neuronal activity, and therefore is not dead according to the brain death criterion used for legal subjects, destroying that organoid would imply to breach the dignity and the rights - first and foremost the right to life of a legal entity.“ Die Autoren fahren dann aber fort: „This argument, however, does not seem robust enough from a legal perspective." - Zum argumentativen Bezug zum Hirntod noch unten 15.3.1.

26 Bayne et al. (2020: 14). 


\subsection{Der rechtliche Status von Hirnorganoiden nach geltendem Recht}

\subsubsection{Hirnorganoide als menschliche Lebewesen ${ }^{27}$}

Die Herstellung von Hirnorganoiden würde zahlreiche fundamentale Rechtsfragen heraufbeschwören, wenn sie eine Entwicklungsfähigkeit wie menschliche Embryonen aufweisen würden. Insbesondere wenn ihnen Bewusstsein ${ }^{28}$ oder gar kognitive Fähigkeiten ${ }^{29}$ zukämen, könnte ihnen rechtlich gesehen Menschenwürde (Art. 1 GG) und Lebensschutz (Art. 2 Abs. $1 \mathrm{GG}$ ) zuzuweisen sein. Dies könnte gemäß einer in der Literatur vertretenen Auffassung dann bejaht werden, wenn man den Beginn des „Hirnlebens“ (etwa am 57. Tag p.c.) als entscheidend für den vollen rechtlichen Schutz des werdenden menschlichen Lebens annimmt ${ }^{30}$ und ein Hirnorganoid irgendwann einmal vergleichbare Fähigkeiten aufweisen würde ${ }^{31}$ (zumal ja auch umgekehrt am Ende des Lebens der Hirntod verbreitet als entscheidende Zäsur betrachtet wird) ${ }^{32}$. Ebenfalls mit vergleichendem Blick auf die Embryonalentwicklung wird die in anderen Rechtsordnungen geltende sog. 14-Tage-Regel (keine in vitro-Entwicklung von Embryonen über den 14. Tag hinaus $)^{33}$ häufig an die Annahme geknüpft, dass etwa am 14. Tag der embryonalen Entwicklung mit dem Auftreten des Primitivstreifens die ersten Anzeichen eines sich

27 Dazu bereits kurze Überlegungen des Verfassers (Taupitz, 2020a: 810; Taupitz, 2020b: 222), die im Folgenden jedoch erheblich verfeinert werden.

28 Zur umstrittenen Frage der Relevanz von (mehr oder weniger) ausgeprägtem Bewusstsein für die Zuschreibung eines besonderen moralischen Status siehe Lavazza (2021: 6). - Ein Problem resultiert zudem daraus, dass es bislang kein einheitliches, zwischen Neurowissenschaften und Philosophie/ Rechtswissenschaften geteiltes Verständnis von Bewusstsein gibt und selbst innerhalb der Naturwissenschaften unterschiedliche Konzepte existieren, siehe Baars/Franklin (2007); Singer (2019); Schick$\operatorname{tanz}$ (2020: 200 f.); IAG Gentechnologiebericht (2020: 25 f.); Baertschi et al. (2020: 12 ff.); Bayne et al. (2020: 13); Sharma et al. (2020: 49 f.); Hyun et al. (2020: 5).

29 Dazu Koplin/Savulescu (2019: 764).

30 Sass (1989: 160/191); IAG Gentechnologiebericht (2020: 19); weitere Nachweise bei Müller-Terpitz (2007: 182 ff.); zu unterschiedlichen Ansätzen siehe ferner Koplin/Savulescu (2019: 762).

31 Immerhin behaupten Forscher, es sei ihnen bereits gelungen, Hirnorganoide über zehn Monate am Leben zu erhalten und EEG-Signale zu messen. Diese sollen eine Komplexität erreicht haben, wie sie auch bei Frühgeborenen in der 28. Gestationswoche auftreten (Trujillo et al., 2019: 558 ff.); allerdings wird der Vergleich mit den Hirnaktivitäten von frühgeborenen Kindern von anderen Forschern als zu weitgehend abgelehnt (siehe Begley, 2019; Parsch, 2019a; Cepelevicz, 2020).

32 Zu diesem Argument Lavazza/Pizzetti (2020: 8 ff).

33 Zur Verbreitung der 14-Tage-Regel siehe Matthews/Moralí (2020). 
ausbildenden Nervensystems und damit von Schmerzempfinden entstehen. ${ }^{34}$ Wenn der moralische, und nach zum Teil vertretener Auffassung auch der rechtliche, Status von Embryonen ${ }^{35}$ in dieser Form mit der beginnenden Gehirnentwicklung bzw. mit der beginnenden Ausprägung von Empfinden/Bewusstsein ${ }^{36}$ verknüpft wird ${ }^{37}$ könnte es naheliegen, weit entwickelte zerebrale Organoide und die Forschung mit ihnen den gleichen Regeln wie denjenigen zum Umgang mit Embryonen zu unterwerfen. ${ }^{38}$ Vom geltenden Embryonenschutzgesetz (ESchG) wäre ihre Verwendung für Forschungszwecke allerdings nur dann gemäß § 2 Abs. $1 \mathrm{ESchG}^{39}$ verboten, wenn sie der Definition des Embryos in $\S 8 \mathrm{ESch}^{40}$ unterstellt werden können; dies ist mehr als zweifelhaft, da die zerebralen Organoide nicht über eine Befruchtung entstanden sind..$^{41}$ Ihre Herstellung wäre zudem unter Umständen verboten, wenn sie die gleiche Erbsubstanz wie ein an-

34 Hostiuc et al. (2019: 119); Cepelevicz (2020); Jácomo (2020); McCully (2021: 1); Matthews et al. (2021: 47/49); Lavazza (2021: 3) mit weiteren Nachweisen. Nach neueren Erkenntnissen existieren im Embryo jedoch mindestens bis zum Tag 28 keinerlei funktionale Nervenverbindungen oder sensorische Systeme, siehe Hurlbut et al. (2017: 1032); Appleby/Bredenoord (2018: 2).

35 Für bedeutsam hält z. B. auch das Bundesverfassungsrecht die Zäsur etwa am 14. Tag der Entwicklung, siehe BVerfGE 39, 1 ff. Rdnr. 133: „Leben im Sinne der geschichtlichen Existenz eines menschlichen Individuums besteht nach gesicherter biologisch-physiologischer Erkenntnis jedenfalls vom 14. Tage nach der Empfängnis (Nidation, Individuation) an“.

36 Die Fähigkeit, Schmerz zu empfinden, wird allgemein als ein Merkmal des Bewusstseins angesehen (Bitar, 2020).

37 Allerdings wird von anderen Autoren in Abrede gestellt, dass die 14-Tage-Regel dazu gedacht war, den Beginn des moralischen Status von menschlichen Embryonen festzulegen; vielmehr sei sie ein Instrument der öffentlichen Politik, das dazu diene, einen Raum für wissenschaftliche Untersuchungen zu schaffen und gleichzeitig Respekt für die unterschiedlichen Ansichten zur Forschung an menschlichen Embryonen zu zeigen, siehe Hyun et al. (2021: 998); Hyun et al. (2016: 170); Cavaliere (2017: 3 f.); siehe auch Chan (2018: 229); weitere Nachweise bei Matthews et al. (2021: 48).

38 So in der Tat Hostiuc et al. (2019: 119-121); Bitar (2020); weitere Nachweise bei Jácomo (2020: 7); siehe auch Greely, zitiert von Cepelevicz (2020): „[...] the more human [...] [the brain organoid] gets, the more you're backing into the same sorts of ethics questions that are the reasons why you can't just use living humans“. - Zugleich wird nicht zuletzt mit Blick auf die Forschung mit Hirnorganoiden dafür plädiert, die 14-Tage-Regel z. B. auf 28 Tage auszudehnen, siehe Appleby/Bredenoord (2018: 3 f.).

$39 \S 2$ Abs. $1 \mathrm{ESchG}$ verbietet die Verwendung eines Embryos ,zu einem nicht seiner Erhaltung dienenden Zweck“.

40 „Als Embryo im Sinne dieses Gesetzes gilt bereits die befruchtete, entwicklungsfähige menschliche Eizelle vom Zeitpunkt der Kernverschmelzung an, ferner jede einem Embryo entnommene totipotente Zelle, die sich bei Vorliegen der dafür erforderlichen weiteren Voraussetzungen zu teilen und zu einem Individuum zu entwickeln vermag."

41 Zum Streit, inwieweit Entitäten, die nicht durch Befruchtung entstanden sind, der Definition des Embryos unterfallen, siehe Taupitz (2014a: Rdnrn. 48 ff.); Dederer (2020b: 55 ff.); Gassner/Opper (2020: $260 \mathrm{f.}, 272 \mathrm{f}$.$) .$ 
derer Embryo, ein Foetus, ein Mensch oder ein Verstorbener aufweisen würden. ${ }^{42}$ Denn dann könnte ein Verstoß gegen § 6 ESchG (Verbot des Klonens) bejaht werden. Aber auch dies ist mehr als zweifelhaft. ${ }^{43}$

Vor allem aber gilt Folgendes: Da der Mensch (und damit auch ein Embryo) nicht auf einzelne Merkmale wie Schmerzempfinden oder Bewusstsein reduziert werden kann, und da sich Hirnorganoide anders als Embryonen nicht zu einem ganzheitlichen Organismus ${ }^{44}$ oder gar Menschen entwickeln können, ${ }^{45}$ ist ein gleichartiger Schutz, wie er für Embryonen im ESchG vorgesehen ist, weder aus dem geltenden Recht ableitbar noch verfassungsrechtlich geboten. ${ }^{46}$ Dies gilt ungeachtet der Tatsache, dass selbst das ESch nicht eins zu eins das abbildet, was von Verfassungs wegen in Bezug auf den Schutz von Embryonen gefordert ist, ${ }^{47}$ und gilt selbst dann, wenn es einmal zur Schaffung menschlicher zerebraler Organoide kommen sollte,

die größer sind als die derzeitigen, die sowohl mit sensorischen Rezeptoren als auch mit organischen (Muskel-) oder künstlichen Effektoren verbunden sind und die trotz morphologischer und funktioneller Unterschiede eine koordinierte elektrische Aktivität aufweisen, die der des Gehirns eines Neugeborenen recht ähnlich ist. $^{48}$

42 Da die Hirnorganoide nicht durch Befruchtung entstehen, sind die Vorschriften des ESchG, die die Verwendung von Eizellen zu anderen Zwecken als der Herbeiführung einer Schwangerschaft verbieten ( 11 Abs. 1 Nr. 2, Abs. 2 ESchG), nicht einschlägig.

43 Sehr umstritten ist, inwiefern es für die Anwendbarkeit des Klonierungsverbots auf die Art der Herstellung der entsprechenden Entität ankommt, siehe Günther (2014: Rdnrn. 3 ff.); Taupitz (2014a: Rdnrn. 48 ff.); Gassner/Opper (2020: 260 f., 272 f.).

44 Faltus (2021: 133).

45 Schicktanz (2020: 200); Koplin/Savulescu (2019: 762). Da das Potenzialitätsargument im Verbund mit dem Speziesargument, dem Kontinuitätsargument und dem Identitätsargument („SKIP“) nach verbreiteter Auffassung den besonderen moralischen und rechtlichen Status des Embryos begründen soll (Müller-Terpitz, 2007: 49-65), muss konsequenter Weise auch umgekehrt gelten, dass Entitäten, die dieses Potenzial nicht aufweisen, keinen vergleichbaren Schutz genießen können. - Für irrelevant halten Hostiuc et al. (2019: 120) das fehlende Potenzial von Hirnorganoiden zur Ganzheitsbildung.

46 In diesem Sinn auch Dederer (2020a: 43): „Klar ist zu diesem Zeitpunkt [...], dass Gehirn-Organoide nicht als Menschen einzustufen sind.“; siehe auch National Academies (2021: 96); Hyun, zitiert von Gogol (2018): „An organoid is not a human subject, according to federal regulations“.

47 Taupitz (2014b: Rdnr. 5) mit zahlreichen Nachweisen; siehe auch BVerfGE 39, 1 (45): „Der Gesetzgeber ist grundsätzlich nicht verpflichtet, die gleichen Maßnahmen strafrechtlicher Art zum Schutze des ungeborenen Lebens zu ergreifen, wie er sie zur Sicherung des geborenen Lebens für zweckdienlich und geboten hält". Dem Gesetzgeber steht deshalb bezogen auf den Embryonenschutz ein weiter Gestaltungsspielraum offen, siehe Dreier (2013: Rdnr. 114); Dederer (2020b: 61).

48 Lavazza/Pizzetti (2020: 7); siehe auch Koplin/Savulescu (2019: 764). 
Ein so starker rechtlicher Schutz wäre wegen der im Vergleich zu Embryonen andersartigen Art der Herstellung unter Vermeidung einer Befruchtung, wegen der Entstehung in einem völlig anderen Kontext und mit einem ganz anderen Ziel als der Erzeugung von Nachkommen, ${ }^{49}$ wegen der gänzlich unterschiedlichen phänotypischen Gestalt ${ }^{50}$ und wegen der auch nicht ansatzweise vorhandenen Fähigkeiten eines „normalen" menschlichen Gehirns, für einen Organismus zentrale Integrations-, Regulations- und Koordinationsleistungen zu vollbringen, nicht überzeugend. ${ }^{51}$ Höhere Hirnaktivitäten oder gar ein Bewusstsein werden die Hirnorganoide auf absehbare Zeit nicht entwickeln können. Dazu fehlt es ihnen an Komplexität. Das menschliche Gehirn enthält eine Vielzahl von Kernzentren, die in der Kommunikation miteinander unterschiedliche Aufgaben erledigen. Hirnorganoide in vitro können vermutlich allenfalls die Funktion einzelner Zentren nachbilden. ${ }^{52}$ Ihre Größe wird im Übrigen schon dadurch eingeschränkt, dass es bisher nicht gelungen ist, sie in einen Blutkreislauf einzubinden..$^{53}$ Dies hat zur Folge, dass sie sich nach etwa einigen Monaten nicht mehr weiter entwickeln, vielmehr von innen absterben, weil Nährstoffe die inneren Zellen nicht erreichen. Das ist auch einer der Gründe, warum die Gebilde kaum größer als ein paar Milli- oder Zentimeter werden. ${ }^{54}$

Deshalb führt auch der vergleichende Blick auf den Hirntod als entscheidende Zäsur am Ende des Lebens ${ }^{55}$ nicht weiter. Denn absehbarer Weise wird ein zerebrales Organoid nie in der Lage sein, vergleichbar einem Gehirn die für einen gesamten Organismus notwendige Integrationsleistung zu erbringen, ohne die dieser Organismus

49 Vgl. zu derartigen Gesichtspunkten für die Beurteilung künstlich hergestellter Entitäten Taupitz (2001: 3440); ähnlich später Deutscher Ethikrat (2011: 100); siehe auch Gassner/Opper (2020: 272 f.); weitere Nachweise zu entsprechenden Überlegungen in der angelsächsischen Literatur im Hinblick auf den moralischen Status früher Embryonen bei Hostiuc et al. (2019: 119).

50 Zur Bedeutung der Ebenbildlichkeit für die Anerkennung einer Entität als „Mensch“ im Sinne der Menschenwürdegarantie: Dederer (2020b: 74).

51 Koplin/Savulescu (2019: 761); Hyun et al. (2020: 5); Baertschi et al. (2020: 14); siehe aber auch Lavazza (2020: 117): „In fact, they are neither physically autonomous nor able to give rise to an adult human being. Yet the brain is the key organ of the person, the one from which one can deduce the presence of life in a person and which, if conscious, even though in a dish, should be considered a person, with increasing moral value the greater its consciousness.“ - Relativierend dann aber ebenda (123): „This characteristic of cerebral organoids makes them morally special, even though they cannot be considered persons in the full sense."

52 Baertschi et al. (2020: 14). - Zu den Versuchen, modular zusammengesetzte Organoidsysteme zu erzeugen, siehe Marton/Pasca (2019); Bagley et al. (2017).

$53 \mathrm{Zu}$ Versuchen, durchblutete Hirnorganoide zu erzeugen, siehe Shou et al. (2020).

54 Chen et al. (2019: 463 f.); Tanaka/Park (2020: 122); unter anderem deshalb ist die Übertragung auf Tiere für die Forscher so interessant.

55 Siehe oben bei Fn. 32. 
nicht als leibseelische Ganzheit existieren könnte. ${ }^{56}$ Eine solche Integrationsleistung umfasst sowohl mentale als auch organismische Aspekte; mentale Prozesse sind ohne organismische Grundlage nicht denkbar. ${ }^{57}$ Der Hirntod wird gerade deshalb als Tod des Menschen angesehen, weil kein anderes Organ die Funktion übernehmen kann, sich mit sämtlichen anderen Organen, von denen jedes einzelne für das Weiterleben des Gesamtorganismus durchaus notwendig sein mag, zu eben jener funktional interaktiven Gesamtheit zu integrieren, die den lebenden Organismus ausmacht und die eben weitaus mehr ist als eine Menge aneinander gekoppelter Einzelorgane. Das Gehirn ist das zentrale Integrations-, Regulations- und Koordinationsorgan. Es integriert die sensorischen und sensiblen Reize aus dem Organismus selbst und von außerhalb über die sogenannten Afferenzen, ermöglicht über die Efferenzen die motorischen Leistungen und die Kommunikation (z. B. über Sprache, Gestik, Mimik), reguliert die Abstimmungsvorgänge in und zwischen den anderen Organsystemen über das vegetative Nervensystem einschließlich der hormonellen Steuerung und ist schließlich die Grundlage des Mentalen und der Subjektivität. ${ }^{58}$

Alles das wird bei einem zerebralen Organoid auch nicht ansatzweise möglich sein. Und ebenso wie ein rein mentalistisches Todesverständnis unangemessen ist, ${ }^{59}$ ebensowenig kann ein auf rein mentalistische Fähigkeiten bezogenes Status- und Schutzkonzept überzeugen. ${ }^{60}$

Insgesamt ist zerebralen Organoiden kein vergleichbarer Status wie Embryonen zuzuschreiben. Das gilt auch für sehr weit entwickelte Hirnorganoide.

\subsubsection{Hirnorganoide als Sachen}

Organoide, die lediglich die Entwicklungsfähigkeit und Leistung von einzelnen Organen aufweisen, sind rechtlich nicht anders $\mathrm{zu}$ behandeln als andere menschliche Organe oder Zellstrukturen auch. ${ }^{61}$ Sie haben - trotz des Umstandes, dass ihre Zellen menschlichen Ursprungs sind und sie in diesem Sinne der Spezies Mensch zugehörig

56 Koplin/Savulescu (2019: 762 ff.); deshalb überzeugt das Hirn-Leben-Kriterium auch nicht als normativer Anknüpfungspunkt für den Beginn des (embryonalen) Lebensschutzes, siehe Müller-Terpitz (2007: 184 ff.) mit zahlreichen weiteren Nachweisen.

57 Deutscher Ethikrat (2015: 73).

58 Ebd.

59 Ebd.: 68.

60 In dieser Richtung auch Koplin/Savulescu (2019: 762); Lavazza/Pizzetti (2020: 10 ff.).

61 So auch Faltus (2021: 133). 
sind ${ }^{62}$ - keinen besonderen intrinsischen rechtlichen Status. Vom menschlichen Körper getrennte Substanzen sind Rechtsobjekte und nicht mehr Bestandteil des Rechtssubjekts. ${ }^{63}$ Es handelt sich nach deutschem Recht um Sachen, an denen Eigentum nach $\S \S 903 \mathrm{ff}$. des Bürgerlichen Gesetzbuches (BGB) bestehen kann. ${ }^{64}$ Zwar ist der (lebende) menschliche Körper keine eigentumsfähige Sache; ${ }^{65}$ mit der Trennung vom Körper unterfällt der nun selbstständige Körperteil aber dem Sachenrecht des BGB. ${ }^{66}$ Dabei wird in der Regel der Forscher durch „Verarbeitung oder Umbildung eines oder mehrerer Stoffe [der Ausgangszellen] eine neue bewegliche Sache“, nämlich das Hirnorganoid, hergestellt haben, sodass er gemäß § 950 BGB (spätestens in diesem Moment ${ }^{67}$ originär das Eigentum daran erwirbt. ${ }^{68}$

Sofern sich genetisches Material des Spenders der Ausgangszellen in dem Hirnorganoid fortsetzt, erstreckt sich allerdings auch das Allgemeine Persönlichkeitsrecht des Spenders auf das Hirnorganoid. Denn nach allgemeiner Ansicht setzt sich das Allgemeine Persönlichkeitsrecht eines Menschen an dem von seinem Körper getrennten Körpermaterial fort ${ }^{69}$ Es bestehen dann an dem Körpermaterial zwei Rechte mit unterschiedlichem Geltungsbereich: Das Eigentumsrecht des Forschers ermöglicht ihm, andere von der Nutzung auszuschließen und selbst nach Belieben damit zu verfahren - allerdings nur, so fügt das Gesetz in § 903 BGB zu den „Befugnissen des Eigentümers“ selbst hinzu, ,soweit nicht Rechte Dritter entgegenstehen“. Und tatsächlich hat der ursprüngliche Träger des Körpermaterials auch ohne die Eigentumsposition weiterhin Rechte an „seinen“ Körpersubstanzen, und zwar in Gestalt seines Allgemeinen Persönlichkeits-

62 Siehe aber Lavazza (2020: 116): Gehirnorganoide „are human by definition, as they come from human cells, and this biological affiliation could grant them a moral status.“ Gegen eine „spezies-zentrische" Argumentation Schicktanz (2020: 199).

63 Roth (2009: 65); Roidis-Schnorrenberg (2016: 56).

64 In anderen Rechtsordnungen wird das zum Teil anders gesehen, siehe Boers et al. (2016: 938): „human tissue is neither a person nor a thing".

65 Ausführliche Darstellung in jüngster Zeit bei Schreiber (2019: 25 ff.); siehe auch EuGH, C-377/98, Kingdom of the Netherlands v European Parliament and Council of the European Union, European Court reports 2001, I-07079, Rdnr. 73: „Somit kann ein Bestandteil des menschlichen Körpers [...] Teil eines Erzeugnisses sein, das durch ein Patent geschützt werden kann, aber er kann in seiner natürlichen Umgebung nicht Gegenstand einer Aneignung sein." (Hervorhebung vom Verfasser).

66 Auf die umstrittene Frage, wie die Entstehung des Eigentums im Zeitpunkt der Trennung vom Körper begründet werden kann, muss hier nicht eingegangen werden, siehe dazu Schreiber (2019: $41 \mathrm{ff}$.); zur internationalen Diskussion siehe etwa die Nachweise bei Boers et al. (2016).

67 Wer zum Zeitpunkt der Trennung vom Körper Eigentum an den Körpersubstanzen erwirbt, ist umstritten, siehe Schreiber (2019: $42 \mathrm{ff}$.).

68 Ehrlich (2000: 57 ff.); Zech (2007: 99 ff.); Schreiber (2019: 322).

69 Schröder/Taupitz (1991: 42 ff.); ausführliche Übersicht über die in Nuancen unterschiedlichen Auffassungen bei Schreiber (2019: 41 ff.). 
rechts. Das kann man auf zweierlei Art begründen: ${ }^{70}$ Entweder kann man sagen, dass sich das Persönlichkeitsrecht, das dem lebenden Menschen zukommt, an den getrennten Körperteilen fortsetzt, gewissermaßen weiter daran klebt. Oder aber man prüft, ob die konkrete Nutzung der Substanz „Fernwirkungen“ auf die Person des früheren Trägers hat und damit das dort bestehende Persönlichkeitsrecht berührt. Beide Wege führen zum selben Ergebnis: ${ }^{71}$ In der deutschen Rechtsordnung ist anerkannt, dass die Ausübung von Eigentümerbefugnissen der einen Person durchaus als Eingriff in das Persönlichkeitsrecht einer anderen Person anzusehen sein kann. Zu denken ist an das Urheberpersönlichkeitsrecht, aufgrund dessen sich der Künstler auch gegenüber dem jetzigen Eigentümer gegen eine Umgestaltung „seines“ Kunstwerkes wehren kann. Ähnliches gilt für Briefe und andere Schriftstücke: Obwohl regelmäßig der Empfänger Eigentum daran erlangt, kann der Verfasser anerkanntermaßen aufgrund seines Persönlichkeitsrechts bestimmte Verwendungsformen, etwa die Veröffentlichung, untersagen. Auch zu Körpersubstanzen kann eine intensive persönliche Beziehung bestehen, die durch eine Weitergabe an Dritte nicht vollkommen erlischt. Durch Genomanalyse kann ein Bild von der körperlichen Disposition des ehemaligen Trägers gezeichnet werden (zu Fragen des Datenschutzes in Bezug auf Neurodaten siehe Molnár-Gábor/Merk, Kap. 16). Ein solcher Rückschluß auf den früheren Träger kann dessen „Geheim-“ und „Intimbereich“ nicht minder berühren als ein Rückschluß aus schriftlichen Äußerungen. Und etwa die Übertragung von Körperzellen oder Organen auf andere Personen steht wertungsmäßig auf gleicher Stufe wie die Umgestaltung eines Kunstwerkes und die damit bewirkte Verletzung der geistigen Beziehung des Künstlers zu seinem Werk. Die Schlussfolgerung lautet daher: Jede Nutzung menschlicher Körpersubstanzen ist darauf zu überprüfen, ob sie das Persönlichkeitsrecht des früheren Trägers verletzt. Für die Bewertung sind neben der Art und dem Ziel der Verwendung sowie der Menge des verwendeten Materials auch die weiteren Konsequenzen für den ursprünglichen Träger und dabei vor allem die Art und das Ausmaß der Anonymisierung entscheidend. Weiter ist von Bedeutung, ob das Material mit seinen (und womöglich gerade wegen seiner) individuellen Eigenschaften auf andere Personen übertragen werden soll und - bezogen auf Forschung - ob das Forschungsprojekt in rechtlicher oder ethischer Hinsicht Bedenken aufwirft. ${ }^{72}$ Da menschlichen Hirnzellen eine besondere - nicht zuletzt anthropologische - Bedeutung beigemessen wird, hat der Spender bezogen auf ein Hirnorganoid, in dem Zellen oder jedenfalls Genmaterial von ihm selbst enthalten sind, das

70 Siehe Taupitz (1991: 209 f.).

71 Zum Folgenden Taupitz (1991: 210-211); Schröder/Taupitz (1991: 43-44).

72 Taupitz (2020a: 805/808); Taupitz (2020b: 212/216) mit weiteren Nachweisen. 
Recht, über die Herstellung und Verwendung des zerebralen Organoids zu bestimmen, indem dafür seine spezifische Einwilligung erforderlich ist. ${ }^{73}$

Für die Erzeugung und Verwendung von Hirnorganoiden ist zudem wichtig, dass beides nicht im rechtsfreien Raum stattfindet. Forschung mit menschlichen Körpermaterialien unterliegt in weiten Teilen den Regeln des ärztlichen Berufsrechts zur Forschung mit menschlichen Körpermaterialien, woraus insbesondere eine Pflicht zur berufsrechtlichen und berufsethischen Beratung durch eine Ethik-Kommission vor Durchführung des Forschungsvorhabens folgt (vgl. § 15 der [Muster-]Berufsordnung für die in Deutschland tätigen Ärztinnen und Ärzte). ${ }^{74}$ Dies entspricht Art. 22 der Empfehlung des Europarates zur Forschung mit menschlichem biologischem Material ${ }^{75}$ und gilt nach dem Tierschutzgesetz auch für Forschung mit Tieren. ${ }^{76}$ Aber auch darüber hinaus verlangen viele Institutionen von den ihnen angehörenden Forschern bzw. fordern Förderinstitutionen die Einschaltung einer Ethik-Kommission. ${ }^{77}$ Gerechtfertigt ist dies aus der Verantwortung des Forschers im Sinne forschungsbegleitender Reflexion, Information und kritisch prüfenden Diskurses ${ }^{78}$ und ermöglicht einen unabhängigen Blick auf das Vorhaben.

\subsubsection{Hirnorganoide als Handelsgut?}

Es stellt sich die Frage, ob Hirnorganoide als Handelsgut in Betracht kommen, ob sie also mit anderen Worten verkauft werden dürfen.

Mit menschlichen Organen und Geweben (wozu auch einzelne Zellen gehören, siehe $\S 1 \mathrm{a}$ Nr. 4 TPG) darf gemäß § 17 Abs. 1 Satz 1 TPG kein Handel getrieben werden; ein Verstoß ist gemäß § 18 TPG strafbar. Dies gilt allerdings nur, wenn die Organe oder Gewebe „einer Heilbehandlung eines anderen zu dienen bestimmt sind“. Das Verbot

73 Siehe die Nachweise oben Fn. 7. Die (nach allgemeinen Grundsätzen ohnehin bestehende) Möglichkeit eines Verbots wird gefordert von Farahany et al. (2018: 431 f.); Schicktanz (2020: 198).

74 Fassung von 2018, siehe unter: https://www.bundesaerztekammer.de/fileadmin/user_upload/ downloads/pdf-Ordner/MBO/MBO-AE.pdf [08.02.2021].

75 Recommendation $\mathrm{CM} / \operatorname{Rec}(2016) 6$ of the Committee of Ministers to member States on research on biological materials of human origin, siehe unter: https://search.coe.int/cm/Pages/result_details. aspx?ObjectID=090000168064e8ff [10.01.2021].

76 Taupitz (2020a: 813); Taupitz (2020b: 229 f./233).

77 Siehe den DFG-Leitfaden für die Antragstellung Projektanträge S. 7 unter: https://www.dfg.de/ formulare/54_01/54_01_de.pdf [10.01.2021]; ferner die „Empfehlung für die Bewertung forschungsbezogener Biobanken durch Ethik-Kommissionen“ des Arbeitskreises Medizinischer Ethik-Kommissionen, Version 2.0 gemäß Beschluss vom 10.06.2016, siehe unter: https://www.akek.de/wp-content/ uploads/HandreichungBiobanken.pdf [10.01.2021].

78 Dazu Dickert (1991: 373). 
des Handeltreibens gilt also nicht für Zellen, die zur Herstellung von Hirnorganoiden verwendet werden, sofern diese ihrerseits reinen Forschungszwecken dienen. ${ }^{79}$ Davon wird noch auf lange Zeit auszugehen sein.

Im Übrigen gilt das Verbot nicht für autologe Transplantate (also für solche, die dem Spender selbst wieder implantiert werden $)^{80}$ und für Hirnorganoide selbst in Fällen allogener Transplantation (also bei Transplantation auf eine andere Person) nicht, da Hirnorganoide als in vitro hergestellte Entitäten keine Organe im Sinne des TPG sind. ${ }^{81}$ Sie sind vielmehr Arzneimittel, die aus oder unter Verwendung von Organen oder Geweben hergestellt wurden ${ }^{82}$ und für die das Handelsverbot nicht gilt (siehe $§ 17$ Abs. 1 Satz 2 Nr. 2 TPG). ${ }^{83}$ Insgesamt kann aus dem Transplantationsgesetz somit kein Verbot des Handeltreibens mit Hirnorganoiden abgeleitet werden. Und selbst innerhalb des Anwendungsbereichs des Handelsverbots verbietet das Gesetz nicht

die Gewährung oder Annahme eines angemessenen Entgelts für die zur Erreichung des Ziels der Heilbehandlung gebotenen Maßnahmen, insbesondere für die Entnahme, die Konservierung, die weitere Aufbereitung einschließlich der Maßnahmen zum Infektionsschutz, die Aufbewahrung und die Beförderung der Organe oder Gewebe. (§ 17 Abs. 1 Satz 2 Nr. 1 TPG) ${ }^{84}$

Fraglich ist allerdings, ob nicht über das geltende Transplantationsgesetz hinaus Hirnorganoide als Gegenstände einzuordnen sind, mit denen kein Handel getrieben werden darf. Immerhin wird es von einigen internationalen Regelwerken ausdrücklich missbilligt, den menschlichen Körper und seine Teile als solche zum Gegenstand finanziellen Gewinns zu machen. Zu nennen sind insbesondere Art. 3 Abs. 2 der Europäischen

79 Vgl. Radau (2006: 165); Häberle (2020: Rdnr. 2).

80 Baumann/Kügele (2020: Rdnr. 1).

81 Näher Gerke (2020: 295); Taupitz (2020a: 810 f.); dort wird keineswegs die Auffassung vertreten, Organoide könnten gleichzeitig Organe im Sinne des TPG und Arzneimittel sein (so aber die Interpretation von Faltus [2021: 131]). Vielmehr wird lediglich ausgeführt, dass die Unterscheidung „natürlich - künstlich hergestellt" nicht entscheidend für die Qualifizierung als Organ ist.

82 Taupitz (2020a: 811 f.).

83 Näher Scholz/Middel (2018: Rdnrn. 13 f.); zur Nichtanwendbarkeit des Verbots des Handeltreibens auf substanziell manipulierte Gewebe wie induzierte pluripotente Stammzellen und daraus entwickelte Produkte auch Harder (2020: 170).

84 Gleiches gilt für das sogleich darzustellende Gewinnerzielungsverbot in Art. 21 des Menschenrechtsübereinkommens zur Biomedizin des Europarats, siehe Harder (2020: 164). 
Grundrechtecharta, ${ }^{85}$ Art. 21 des Menschenrechtsübereinkommens zur Biomedizin des Europarats ${ }^{86}$ und Art. 6 der Empfehlung des Europarates zu Forschung mit menschlichem biologischem Material. ${ }^{87}$ Freilich wird in diesen Vorschriften nicht deutlich, ob sie sich lediglich auf den lebenden menschlichen Körper insgesamt (hier also auf die Entnahme von Zellen aus dem menschlichen Körper) beziehen, oder ob auch vom Körper bereits getrennte Substanzen in der nachfolgenden Verwendungskette vom Gewinnerzielungsverbot erfasst sein sollen. Da im Hintergrund des Gewinnerzielungsverbots nach verbreiteter Auffassung die Menschenwürde steht, ${ }^{88}$ menschlichen Körpersubstanzen, die vom Substanzträger bereits getrennt sind, aber keine Menschenwürde zukommt und in ihrer Verwendung grundsätzlich auch keine Menschenwürdeverletzung liegt, ${ }^{89}$ kann sich das Verbot nach überzeugender Auffassung grundsätzlich nur auf den lebenden menschlichen Körper beziehen..$^{90}$ Selbst wenn man dies anders sieht, ${ }^{91}$ können doch in Übereinstimmung mit der herrschenden Meinung jedenfalls unterhalb einer „Relevanzschwelle“92 vom Körper getrennte Körpersubstanzen nicht von den Verboten umfasst sein. Dazu gehören neben abgestoßenen Haaren, Finger- oder Fuß-

85 „Im Rahmen der Medizin und Biologie muss insbesondere folgendes beachtet werden: [...] - das Verbot, den menschlichen Körper und Teile davon als solche zur Erzielung von Gewinnen zu nutzen $[\ldots]$...

86 „Prohibition of financial gain: The human body and its parts shall not, as such, give rise to financial gain." Art. 21 of the Convention for the Protection of Human Rights and Dignity of the Human Being with regard to the Application of Biology and Medicine: Convention on Human Rights and Biomedicine, siehe unter: https://rm.coe.int/168007cf98 [08.02.2021].

87 „Prohibition of financial gain: Biological materials of human origin should not, as such, give rise to financial gain." Art. 6 of the Recommendation CM/Rec(2016)6 of the Committee of Ministers to member States on research on biological materials of human origin, siehe unter: https://search.coe. $\mathrm{int} / \mathrm{cm} /$ Pages/result_details.aspx?ObjectID=090000168064e8ff [08.02.2021].

88 Siehe etwa EuGH, C-377/98, Kingdom of the Netherlands v European Parliament and Council of the European Union, European Court reports 2001, I-07079, Rdnr. 77; Deutscher Bundestag (1996: 29); weitere Nachweise bei Roidis-Schnorrenberg (2016: 80 ff.); Fröhlich (2012: 139 ff.); Radau (2006: 164 ff.) mit Hinweis auf die Inkonsistenzen jedenfalls des deutschen Rechts.

89 Siehe Taupitz (2000: 157); Zech (2007: 118); Schnorrenberg (2010: 236); Roidis-Schnorrenberg (2016: 113 f.); Fröhlich (2012: 161/208), mit dem berechtigten Hinweis, dass eine Menschenwürdeverletzung dann in Betracht kommt, wenn die Körpersubstanz in demütigender Absicht verwendet wird. Das ist aber kein Spezifikum der Verwendung menschlicher Körpersubstanzen, sondern kann auch mit anderem Material (Bild, Tonaufnahme etc.) geschehen.

90 Roidis-Schnorrenberg (2016: 113 f.); siehe auch Halasz (2004: 122 f.).

91 Siehe etwa Borowski (2019: Rdnr. 46); Heselhaus (2017: Rdnr. 24); Breithaupt (2012: 40 ff./59).

92 Borowski (2019: Rdnr. 46); siehe auch Kranz (2008: 183), wonach die Kommerzialisierungsverbote restriktiv auszulegen sind. 
nägeln ${ }^{93}$ nach Sinn und Zweck auch geringe Mengen Restblut ${ }^{94}$ oder wenige Zellen, die im Rahmen eines diagnostischen oder therapeutischen Eingriffs entnommen wurden. Erst recht gilt dies für Zellen, die einem Toten entnommen wurden, weil hier allenfalls das viel schwächere postmortale Persönlichkeitsrecht zu Buche schlagen kann. ${ }^{95}$ Alles dies trifft auch auf Zellen zu, die für die Herstellung von Hirnorganoiden realistischer Weise verwendet werden können, wenn diese denn überhaupt aus Gehirnzellen und nicht etwa aus induzierten pluripotenten Stammzellen generiert wurden. Soweit aus den entnommenen Zellen in einem komplexen Herstellungsprozess eine neue Sache (hier das Hirnorganoid, siehe oben 15.3.2) erzeugt wurde, ist es erst recht fernliegend, diese künstlich hergestellte Sache als nicht verkaufbar anzusehen. Dies gilt vor allem auch unter Berücksichtigung der Tatsache, dass das Verbot der Gewinnerzielung primär mit dem Mangel an geeigneten Spenderorganen und der hieraus erwachsenden Versuchung begründet wird, aus wirtschaftlichen Motiven die gesundheitliche Notlage lebensgefährlich Erkrankter in besonders verwerflicher Weise auszunutzen. Zudem sollen finanzielle Anreize an potenzielle Lebendspender, ihre Gesundheit und körperliche Integrität um wirtschaftlicher Vorteile willen zu beeinträchtigen, unterbunden werden. ${ }^{96}$ Alles das trifft auf künstlich erzeugte Hirnorganoide nicht zu.

Aus rechtlicher Sicht ist zudem von Bedeutung, dass die EU-Grundrechtecharta unmittellbar allein bei der Durchführung von Unionsrecht zum Tragen kommt ${ }^{97}$ und insbesondere Art. 3 Abs. 2 keine unmittelbaren Wirkungen für Privatrechtsbeziehungen entfaltet. ${ }^{98}$ Das Menschenrechtsübereinkommen zur Biomedizin ${ }^{99}$ ist für die Bundesrepublik Deutschland mangels Unterzeichnung und Ratifikation ohnehin nicht verbindlich, und die Empfehlung des Europarates schließlich ist von ihren Verfassern selbst nicht als bindend ausgestaltet.

93 Siehe zu diesen Körpersubstanzen ausdrücklich: Erläuternder Bericht zum Menschenrechtsübereinkommen zur Biomedizin, Mai 1997, Rdnr. 133, siehe unter: https://rm.coe.int/16800ccde5 [08.02.2021]; zu Haaren auch: Commentary of the Charter of fundamental rights of the European Union, Juni 2006, 40, siehe unter: https://sites.uclouvain.be/cridho/documents/Download.Rep/ NetworkCommentaryFinal.pdf [08.02.2021]; siehe auch Breithaupt (2012: 43 ff./57 ff.); Heselhaus (2017: Rdnr. 24).

94 Taupitz (2017: 357). Zu einer Erweiterung der in den offiziellen Erläuterungen (siehe vorige Fn.) aufgeführten Ausnahmen auf andere Körpersubstanzen siehe etwa Schwarzburg (2012: 184 f.).

95 Taupitz (1996: 7 f.).

96 Tag (2017: Rdnr. 3).

97 Art. 51 (1) der Charta; siehe ferner Jarass (2021a: Rdnr. 9).

98 Jarass (2021b: Rdnr. 3); Augsberg (2015: Rdnr. 7); Roidis-Schnorrenberg (2016: 120 ff.); Fröhlich (2012: 176) mit weiteren Nachweisen; Heselhaus (2017: Rdnr. 20).

$99 \mathrm{Zu}$ dem Abkommen ausführlich Taupitz (2002). 
Insgesamt besteht für Hirnorganoide somit kein Verbot des Handeltreibens. Selbst wenn man ein Gewinnerzielungsverbot auf sie anwenden würde, änderte dies nichts an der oben (15.3.2) dargestellten Rechtslage, dass an ihnen Eigentum bestehen kann und das Eigentum auch übertragen werden kann. Der Erwerb und Übergang von Eigentumsrechten wird von einem Gewinnerzielungsverbot nicht erfasst. ${ }^{100}$

\subsubsection{Hirnorganoide als Daten im Sinne des Datenschutzrechts?}

Zum Teil werden menschliche Körpermaterialien als solche wegen des in ihnen enthaltenen genetischen Materials, das Informationen über den früheren Träger enthält, (auch) ${ }^{101}$ als Daten eingeordnet (ausführlich hierzu siehe Molnár-Gábor/Merk, Kap. 16). ${ }^{102}$ Daten haben einen anderen Status als Sachen, was sich schon daran zeigt, dass es an ihnen nach geltendem Recht kein „Eigentum“ gibt. ${ }^{103}$ Wenn man Körpermaterialien (auch) als Daten einordnet, ist jeder Umgang mit ihnen datenschutzrechtlich relevant, sodass etwa schon die physische Erlangung der Proben als Datenerhebung anzusehen ist. ${ }^{104}$ Dies widerspricht allerdings dem erkennbaren Willen des deutschen Gesetzgebers, der in $\S 3$ Nr. 10 und 11 des Gendiagnostikgesetzes ausdrücklich zwischen genetischen Proben und genetischen Daten unterscheidet. ${ }^{105}$ Gleiches gilt für den europäischen Gesetzgeber, der in der Definition der genetischen Daten in Art. 4 Nr. 13 Datenschutz-Grundverordnung (DSGVO) entsprechend differenziert. ${ }^{106}$ Als Gegenargument kann auch nicht angeführt werden, dass Datenträger mit sensiblen Daten in den Anwendungsbereich der DSGVO fallen. ${ }^{107}$ Denn bei humanem Material handelt es sich nicht um vom Menschen geschaffene Datenträger. Das Datenschutzrecht soll geistig vermittelte oder vermittelbare Sachverhalte erfassen, dient es doch dem Schutz der informationellen Selbstbestimmung und somit der Beziehung des Einzelnen zu seinen

100 Borowski (2019: Rdnr. 46); Heselhaus (2017: Rdnr. 24); Jarass (2021b: Rdnr. 16).

101 Diejenigen, die menschliche Körpersubstanzen als Daten einordnen, leugnen damit nicht zugleich ihren Charakter als (eigentumsfähige) körperliche Sachen.

102 Büchner (2010: 123 f.).

103 Hoeren (2019); Determann (2018).

104 Vossenkuhl (2013: 6), sofern das biologische Zellmaterial von vornherein zur Informationserlangung gewonnen wird.

105 Siehe auch Deutscher Bundestag (2008: $22 \mathrm{f}$.).

106 Demnach sind genetische Daten personenbezogene Daten zu den ererbten oder erworbenen genetischen Eigenschaften einer natürlichen Person, die eindeutige Informationen über die Physiologie oder die Gesundheit dieser natürlichen Person liefern und insbesondere aus der Analyse einer biologischen Probe der betreffenden natürlichen Person gewonnen wurden.

107 So aber Ziebarth (2018: Rdnr. 8). 
Daten. ${ }^{108}$ Würde man das Datenschutzrecht entsprechend auch auf natürliche Datenträger ausweiten, müsste das Datenschutzrecht „auf die Aufbewahrung nahezu jeder Sache“ Anwendung finden. ${ }^{109}$ Deshalb sind Körpermaterialien als solche nicht als Daten zu qualifizieren. . $^{110}$

Allerdings handelt es sich unzweifelhaft um eine Datenerhebung, wenn durch die Untersuchung des Materials (neue) Daten generiert werden ${ }^{111}$ oder gar die Spender der Ausgangszellen re-identifiziert werden, ${ }^{112}$ sodass dafür und für die anschließende Verwendung dieser Daten das Datenschutzrecht einschlägig ist, sofern es sich nicht um anonymes Material handelt. ${ }^{113}$ Das betrifft aber die Verwendung des Körpermaterials, hier also des Organoids, nicht aber den Status des Materials (Organoids) selbst.

\subsection{Der rechtliche Status von Hirnorganoiden: Rechtspolitische Überlegungen}

Abschließend ist zu prüfen, ob es bezogen auf Hirnorganoide einer Gesetzesänderung bedarf. Immerhin wird auch Tieren ein besonderer rechtlicher Status zugeschrieben, sind sie doch keine Sachen und werden sie durch besondere Vorschriften (die Tierschutzgesetze) geschützt (§ 90a Satz 1 BGB), auch wenn sie rechtlich weithin wie Sachen behandelt werden ( $\$ 90 a$ Satz 2 BGB). Und aufgrund der zunehmenden Intelligenz und Autonomie von Systemen der Künstlichen Intelligenz (KI) werden Rufe nach einer Gesetzesänderung zur Anerkennung der Rechtsfähigkeit (bestimmter) autonomer Systeme lauter. ${ }^{114}$ Die Vorschläge reichen dabei von einer eng umgrenzten Teilrechtsfähigkeit bis hin zur vollumfänglichen Rechtsfähigkeit („E-Person“). ${ }^{115}$ Dies könnte auch ein Vorbild für die rechtliche Einordnung von Hirnorganoiden sein.

108 Deutscher Bundestag (2008: 22 f.); Schreiber (2019: 102 f.).

109 Breyer (2004: 660).

110 Halasz (2004: 263 f.); Fink (2005: 60); Breithaupt (2012: 240 f.); Koch (2013: 117); Schreiber (2019: 104 f.). 111 Schreiber (2019: 106 f.).

112 Etwa um genetisch Verwandte kontaktieren zu können, z. B. im Fall von Demenzforschung mit den verwendeten Ausgangszellen, siehe dazu Ooi et al. (2020: 450).

113 Nach zum Teil vertretener Auffassung ist humanes genetisches Material allerdings niemals anonym, siehe (diese Auffassung ablehnend) Taupitz (2020c: $608 \mathrm{f}$.).

114 Die Entschließung des Europäischen Parlaments vom 16. Februar 2017 mit Empfehlungen an die Kommission zu zivilrechtlichen Regelungen zur Robotik (2015/2103[INL]) forderte die Kommission auf, die Auswirkungen der „Schaffung eines besonderen Rechtsstatus für Roboter“ und der „Anwendung der elektronischen Persönlichkeit auf Fälle, in denen Roboter intelligente autonome Entscheidungen treffen oder anderweitig selbstständig mit Dritten interagieren“, zu untersuchen.

115 Teubner (2018: 160 ff.); Zech (2020: A 95). 
Allerdings sind beide Bereiche deutlich voneinander zu trennen, ist doch die Begründung jeweils eine andere: Die Idee der Einführung einer „E-Person“ ist von dem Gedanken getragen, dass sich die Entscheidungsabläufe von KI-Systemen denjenigen von Menschen immer mehr annähern und die Systeme damit einen gewissen Grad von Autonomie erreichen. Dabei wird mit dem Begriff „Autonomie“ zum Ausdruck gebracht, dass der Mensch im Hinblick auf die Intransparenz von KI-Entscheidungen ein Stück weit die Kontrolle abgegeben hat. ${ }^{116}$ Dem gegenüber wird bezogen auf Hirnorganoide vor allem auf die Empfindungsfähigkeit und dabei insbesondere auf das mögliche Schmerzempfinden (wie bei Tieren) geblickt. Daraus wird verbreitet geschlossen, dass sie „Interessen“ haben, die moralisch zu berücksichtigen sind. ${ }^{117}$ Außerdem sind die intendierten Folgen jeweils andere: Bei der E-Person geht es vor allem um deren Haftung für die Verursachung von Schäden, die Dritten zugefügt werden ${ }^{118}$ (sodass die E-Person mit eigenem Vermögen ausgestattet werden müsste), während es bezogen auf Hirnorganoide vor allem darum geht, Maßnahmen zu unterbinden, die dem Organoid selbst Schaden (z. B. Schmerzen) zufügen.

Trotz dieser Unterschiede stellt sich in beiden Bereichen gleichermaßen die Kardinalfrage, ab welchem Ausmaß von „Autonomie“ bzw. „Empfindungsfähigkeit“ oder „Bewusstsein“ ein besonderer Status zugesprochen werden sollte. Immerhin können „Autonomie“ bei der KI und „Empfindungsfähigkeit" bzw. „Bewusstsein“ bei Hirnorganoiden graduell mehr oder weniger ausgeprägt vorhanden sein, ${ }^{119}$ sodass die Grenze vom Gesetzgeber dezisionistisch festgelegt werden müsste. Auch müsste entschieden werden, wie man das betreffende KI-System abgrenzen kann, wenn es mit anderen Systemen vernetzt ist, während bezogen auf Hirnorganoide umgekehrt gefragt werden müsste, welche zusätzlichen Attribute wie Schmerzrezeptoren oder Sinnesorgane, die Informationsgehalte über die Außenwelt vermitteln, ${ }^{120}$ erforderlich sind, um den besonderen Status zuzusprechen. Für Hirnorganoide ergibt sich das zusätzliche Problem, wie die entsprechende Fähigkeit - über die Messung z. B. rein elektrischer Ströme hinaus - festgestellt werden kann, da ein Hirnorganoid als solches nicht kommunizieren kann und „Schmerzempfinden“ oder „Bewusstsein“ allenfalls über (ihrerseits umstrittene) ${ }^{121}$ Korrelate „gemessen“ werden können. ${ }^{122}$

116 Mühlböck/Taupitz (2021: 183).

117 Koplin/Savulescu (2019: 763 f.); Lavazza (2021: 3/6); Lavazza/Massimini (2018: 609).

118 Mühlböck/Taupitz (2021: 214).

119 Lavazza (2020: 107); zu Systemen der Künstlichen Intelligenz Mühlböck/Taupitz (2021: 215).

120 Dazu Baertschi et al. (2020: 14); Faltus (2021: 133).

121 Doerig (2019); Lavazza (2021: 5 f.).

122 Bayne et al. (2020: 11 ff.); Koplin/Savulescu (2019: 762); Singer (2019); Farahany et al. (2018: 431); Lavazza/Massimini (2018: 608); Lavazza (2020: 112/114). 
Auf dem Boden des deutschen (und europäischen) ${ }^{123}$ Rechts geht es richtigerweise überhaupt nicht um eigene (intrinsische) Rechte von Hirnorganoiden, ${ }^{124}$ schon gar nicht vergleichbar jenen von Embryonen oder gar geborenen Menschen (siehe oben 15.3.1), sodass auch die vereinzelt geäußerte Überlegung abwegig ist, ihnen einen Betreuer an die Seite zu stellen. ${ }^{125}$ Wie bezogen auf Tiere geht es allenfalls um mögliche (Schutz-) Pflichten des Menschen ihnen gegenüber ${ }^{126}$ oder um objektivrechtliche Grenzen der Forschung aus über-individuellen Gründen - so wie übrigens auch das Zusprechen eines besonderen „moralischen Status“ nicht binär ist (,alles oder nichts“), ${ }^{127}$ sondern ganz unterschiedliche Ausprägungen und vor allem Konsequenzen haben kann, ${ }^{128}$ also keineswegs per se das Zuerkennen von Rechten oder des „Status“ eines geborenen Menschen bedeutet. ${ }^{129}$ Speziell bezogen auf Hirnorganoide wird in der internationalen Diskussion denn auch ganz überwiegend lediglich gefordert, weit entwickelten zerebralen Organoiden ein „gewisses Maß an moralischem Status“ („some degree of moral status“) zuzuerkennen, falls sie wirklich Charakteristika wie Bewusstsein, Schmerzempfinden oder Selbsterkenntnis entwickeln würden. ${ }^{130}$ Zugleich wird allerdings selbst insoweit betont, dass man noch sehr weit davon ${ }^{131}$ und erst recht von einem „Gehirn aus dem

123 Lavazza/Pizzetti (2020: 22): „,...] based on Italian law and European law as a superordinate system [...], it must in fact be concluded that HCOs [human cerebral organoids] have no right to any special legal protection, as they do not fall into any category other than that of biological material [...]".

124 Manche befürchten gar, dass das Konzept von Menschenwürde unterminiert würde, wenn Hirnorganoide denselben Rechtsstatus wie (geborene) Menschen zugesprochen bekämen, siehe Lavazza/ Pizzetti (2020: 13, Fn. 43).

125 Siehe aber Kaulen (2018).

126 In der Tat wird in der internationalen Debatte häufig ein Schutz von Hirnorganoiden gefordert, der dem von Tieren gleicht, siehe Birch/Browning (2021: 57); Bitar (2020); Koplin/Savulescu (2019: 763 f.); Lavazza/Pizzetti (2020: 12); Sawai et al. (2019: 440) mit weiteren Nachweisen.

$127 \mathrm{Zu}$ dieser Auffassung Iltis et al. (2019: 11).

128 DeGrazia (2008: 181 ff.); Lavazza (2020: 116); Lavazza (2021: 6). Shepherd (2018: 15) beschreibt die Zuerkennung eines moralischen Status als „eine Art Platzhalter für die Zuschreibung von Gründen, eine Entität zu betrachten und eine Entität auf bestimmte Weise zu behandeln“. Ähnlich Iltis et al. (2019: 9) mit weiteren Nachweisen.

129 Lavazza (2020: 123): „This characteristic of cerebral organoids makes them morally special, even though they cannot be considered persons in the full sense." Siehe auch Schicktanz (2020: 198). 130 Koplin/Savulescu (2019: 760); Lavazza/Pizzetti (2020: 14/22).

131 Deutlich Knoblich, zitiert von Bahnsen (2018): „Die Nervenzellen sprechen durchaus miteinander. Aber über Bewusstsein oder Denken auch nur zu spekulieren ist absurd. Emotional ist das verständlich, rational nicht gerechtfertigt." 
Reagenzglas" entfernt ist ${ }^{132}$ und die wissenschaftlich unzutreffende Bezeichnung der Organoide als „Mini-Gehirne“133 völlig übertriebene Besorgnisse ausgelöst hat. ${ }^{134}$

Bezogen auf das deutsche Recht ist weitergehend zu bezweifeln, ob rechtliche Regeln, wie sie in der ethischen Debatte im Ausland erwogen werden (etwa ein Verbot der Kultivierung von weit entwickelten Hirnorganoiden über einen bestimmten Zeitraum $^{135}$ [z. B. die für Embryonen weithin geltende 14-Tage-Frist ${ }^{136}$ und/oder über die Bildung bestimmter Schlüsselbereiche für die Entstehung von Bewusstsein hinaus ${ }^{137}$ bzw. ein Verbot der Durchführung bestimmter Versuche mit dem Hirnorganoid) ${ }^{138}$ überhaupt verfassungskonform wären. Denn in die Wissenschaftsfreiheit des Art. 5 Abs. 3 GG darf nur zum Schutz anderer Güter mit Verfassungsrang eingegriffen werden. ${ }^{139}$ Da Hirnorganoide aber keinen besonderen verfassungsrechtlichen Status haben und angebliche Schutzgüter wie das „Menschenbild unserer Kultur“ oder „kulturelles Selbstverständnis“, auf die im Zusammenhang mit dem Schutz von Embryonen verwiesen wird und die auch bezogen auf Hirnorganoide ins Spiel gebracht werden könnten, ebensowenig wie das Vorsichtsprinzip als solches ${ }^{140}$ Grundrechseinschränkungen legitimieren, ${ }^{141}$ könnte allenfalls das Allgemeine Persönlichkeitsrecht der Spender der Ausgangszellen (Art. 2 Abs. 1 i.V.m. Art. 1 Abs. 1 GG) oder der Tierschutz im Rahmen von Tierversuchen (Art. 20a GG) zu einer Rechtfertigung von Beschränkungen der Hirnorganoidforschung führen. Das Allgemeine Persönlichkeitsrecht der Spender der Ausgangszellen ist aber bereits durch das Erfordernis ihrer konkreten Einwilligung in die Herstellung von Hirnorganoiden und durch das den Spendern damit zukommende Veto-Recht hinreichend gewahrt (oben 15.3.2), und auch dem Tierschutz ist durch das geltende Tierschutzgesetz ausreichend Rechnung getragen. Weitergehenden Beschränkungen der Forschungsfreiheit sind deshalb weder notwendig noch gerechtfertigt. ${ }^{142}$

Verstärkt werden die verfassungsrechtlichen Bedenken gegen Einschränkungen der Hirnorganoidforschung durch den Blick auf etwaige therapeutische Möglichkeiten für

132 Koplin/Savulescu (2019: 761/765); Cepelevicz (2020); Lange (2019); Weiler (2020).

133 Nachweise oben Fn. 14.

134 Lunshof und Greely, zitiert von Cepelevicz (2020).

135 Lavazza/Pizzetti (2020: 20).

136 Jácomo (2020: 7); Bitar (2020).

137 Bitar (2020); Lavazza (2021: 7); National Academies (2021: 97).

138 Reardon (2020: 661); Goodall (2020).

139 Siehe oben 15.2 .

140 Die Anwendung des Vorsichtsprinzips fordern bezogen auf Hirnorganoide Birch/Browning (2021: 56).

141 Vgl. Taupitz (2014b: B. III. Rdnr. 23).

142 Anders aber Birch/Browning (2021: 57): „regulation is urgently needed“. 
Erkrankte; ${ }^{143}$ denn der Staat darf vor dem Hintergrund der Rechte von Patienten auf Leben, körperliche Unversehrtheit und Gesundheit (Art. 2 GG) die Entwicklung und Anwendung möglicher Therapien nicht ohne hinreichenden Grund verbieten. In die Betrachtung einzubeziehen ist auch die ggf. mögliche Vermeidung von Forschung mit Embryonen (soweit sie im Ausland zulässig ist) und Foeten ${ }^{144}$ bzw. Primaten. ${ }^{145} \mathrm{Zu} \mathrm{Recht}$ wird in der internationalen Debatte davor gewarnt, das große Potenzial der Forschung mit Hirnorganoiden vorschnell durch restriktive Regeln versiegen zu lassen. ${ }^{146}$ Dem steht eine Beratung ${ }^{147}$ der Forscher durch Ethik-Kommissionen (siehe oben 15.3.2) nicht entgegen; ${ }^{148}$ dies gilt auch im Fall der Einbeziehung von Tieren. ${ }^{149}$ Dies entspricht weitgehend der Praxis in Deutschland (siehe oben 15.3.2), wobei die Kommissionen ggf. um entsprechenden Sachverstand zu erweitern wären. ${ }^{150}$

\subsection{Zusammenfassung}

- Das deutsche Recht enthält zu Hirnorganoiden keine speziellen Rechtsregeln.

- Hirnorganoide haben denselben Status wie andere menschliche Organe. Sie sind Sachen, an denen Eigentum bestehen kann. Das Eigentum steht in der Regel demjenigen zu, der das Hirnorganoid hergestellt hat. Soweit für die Herstellung der Hirnorganoide menschliche Zellen verwendet werden, bedarf es aufgrund des allgemeinen Persönlichkeitsrechts der Spender*innen der Ausgangszellen ihrer expliziten (informierten) Einwilligung.

- Selbst weit entwickelte Hirnorganoide haben nicht einen rechtlichen Status vergleichbar demjenigen von Embryonen oder gar von geborenen menschlichen Lebewesen. Es ist auch nicht sachgerecht, ihnen einen solchen Status zuzusprechen.

143 Koplin/Savulescu (2019: 763); Lavazza/Pizzetti (2020: 20); National Academies (2021: 97).

144 Lavazza/Massimini (2018: 607).

145 Sidhaye/Knoblich (2021: 53); differenzierend Schicktanz (2020: 196 f.).

146 Koplin/Savulescu (2019: 761); Farahany et al. (2018: 432); diese Warnung müsste allerdings auch Regelungen der Forschungs-Selbstkontrolle/-Selbstbeschränkung erfassen, wie sie oftmals (als Alternative zu gesetzlichen Regelungen) gefordert werden: Reardon (2020: 661); Koplin/Savulescu (2019: 761); Cepelevicz (2020); Chen et al. (2019: 463).

147 Wenn der Forscher nur den Rat einer Ethik-Kommission einholen muss, ist er von Rechts wegen nicht an den Rat gebunden. Das ist anders, wenn er - z. B. gemäß Arzneimittelgesetz - eine Genehmigung vor Durchführung des Forschungsvorhabens einholen muss.

148 Munsie et al. (2017: 944); National Academies (2021: 99 ff.); zu den verfassungsrechtlichen Anforderungen an das Erfordernis, eine Ethik-Kommission einzuschalten, siehe Hufen (2017: $1266 \mathrm{ff}$.).

149 Taupitz (2020a: 813); Taupitz (2020b: 233).

150 Skepsis, ob die bestehenden lokalen Forschungs-Ethik-Kommissionen kompetent genug sind, bei Farahany et al. (2018: 432). 
- Forschung mit Hirnorganoiden, die aus menschlichen Zellen generiert werden, unterliegt weithin der Bewertung durch (ggf. um entsprechenden Sachverstand zu erweiternde) Ethik-Kommissionen; dies gilt auch im Fall der Einbeziehung von Tieren.

- Einer Änderung oder Ergänzung des deutschen Rechts speziell bezogen auf Hirnorganoide bedarf es, schon allein im Hinblick auf den erst am Anfang stehenden Prozess der Herstellung komplexer Organoide, auf absehbare Zeit nicht.

- Über das geltende Recht hinausgehende Beschränkungen der Forschung mit Hirnorganoiden wären im Hinblick auf die Wissenschaftsfreiheit des Art. 5 Abs. 3 GG auch kaum zu rechtfertigen.

\subsection{Literaturverzeichnis}

Appleby, J. B./ Bredenoord, A. L. (2018): Should the 14-day rule for embryo research become the 28-day rule? In: EMBO Mol Med. 10(9).

Augsberg, S. (2015): Kommentierung zu GRC Art. 3. In: von der Groeben, H. et al. (Hrsg.): Europäisches Unionsrecht. 7. Auflage. Nomos, Baden-Baden.

Baars, B. J./Franklin, S. (2007): An architectural model of conscious and unconscious brain functions: Global Workspace Theory and IDA. In: Neural Netw 20: 955-961.

Baertschi, B. et al. (2020): Organoids research: What are the ethical issues?. Unter: https://www.hal. inserm.fr/inserm-03117706/document [15.03.2021].

Bagley, J. A. et al. (2017): Fused cerebral organoids model interactions between brain regions. In: Nat Methods. 14(7): 743-751.

Bahnsen, U. (2018): Hirnforschung: Hier wachsen Gehirne. In: Die Zeit, Online-Publikation 25.04.2018. https://www.zeit.de/2018/17/hirnforschung-neurowissenschaft-organoide-nervenzellenbewusstsein [15.03.2021].

Bartfeld, S. et al. (Hrsg.) (2020): Organoide. Ihre Bedeutung für Forschung, Medizin und Gesellschaft. Nomos, Baden-Baden.

Baumann, G./Kügele, S. (2020): Kommentierung zu § 17 TPG. In: Nomos Bundesrecht, Erläuterungen. Bayne, T. et al. (2020): Are there islands of awareness? In: Trends in Neurosciences 43: 6-16.

Begley, S. (2019): In a first, cerebral organoids produce complex brain waves similar to newborns', reviving ethical concerns. Unter: https://www.statnews.com/2019/08/29/in-a-first-cerebralorganoids-produce-complex-brain-waves-similar-to-newborns-reviving-ethical-concerns/ [21.01.2021].

Birch, J./Browning, H. (2021): Neural organoids and the precautionary principle. In: The American Journal of Bioethics 21: 56-58. DOI: 10.1080/15265161.2020.1845858.

Bitar, M. (2020): Are brain organoids equivalent to philosophical zombies? Online-Publikation 03.04.2020. DOI: 10.20944/preprints202004.0028.v1.

Boers, S. et al. (2016): Organoid biobanking: identifying the ethics. In: EMBO Rep 17: 938-941.

Borowski, M. (2019): Kommentierung zu GRC Art. 3. In: Meyer, J./Hölscheidt, S. (Hrsg.): Charta der Grundrechte der Europäischen Union. 5. Auflage. Nomos, Baden-Baden. 
Breithaupt, J. (2012): Rechte an Körpersubstanzen und deren Auswirkung auf die Forschung mit abgetrennten Körpersubstanzen. Nomos, Baden-Baden.

Breyer, P. (2004): Der datenschutzrechtliche Schutz von Körpersubstanzen, die Patienten zu Analysezwecken entnommen wurden. In: Medizinrecht 22: 660-667.

Büchner, B. (2010): Körpersubstanzen als Forschungsmaterialien. Dr. Kovac, Hamburg.

Cavaliere, G. (2017): A 14-day limit for bioethics: the debate over human embryo research. In: BMC Medical Ethics 18: 38. DOI 10.1186/s12910-017-0198-5.

Cepelevicz, J. (2020): An ethical future for brain organoids takes shape. In: Quantamagazine. Unter: https://www.quantamagazine.org/an-ethical-future-for-brain-organoids-takesshape-20200123/ [21.01.2021].

Chan, S. (2018): How and why to replace the 14-day rule. In: Current Stem Cell Reports 4(3): 228-234.

Chen, H. et al. (2019): Transplantation of human brain organoids: Revisiting the science and ethics of brain chimeras. In: Cell Stem Cell 25(4): 462-472.

Dederer, H.-G. (2020a): Über die Rechte von Gehirn-Organoiden. In: Laborjournal, Online-Publikation 08.05.2020. Unter: https://www.laborjournal.de/rubric/special/special/2020_05_03.php [21.01.2021].

Dederer, H.-G. (2020b): Der manipulierte Embryo: Konsequenzen für das Recht. In: Jahrbuch für Recht und Ethik 28(1): 53-81. Duncker \& Humblot, Berlin

DeGrazia, D. (2008): Moral status as a matter of degree? In: The Southern Journal of Philosophy 46: 181-198.

Determann, L. (2018): Kein Eigentum an Daten. In: MMR 21: 277-278.

Deutscher Bundestag (1996): Entwurf eines Gesetzes über die Spende, Entnahme und Übertragung von Organen (Transplantationsgesetz - TPG). BT-Drucksache 13/4355.

Deutscher Bundestag (2008): Entwurf eines Gesetzes über genetische Untersuchungen bei Menschen (Gendiagnostikgesetz - GenDG). BT-Drucksache 16/10532.

Deutscher Ethikrat (2010): Humanbiobanken für die Forschung. Eigenverlag, Berlin.

Deutscher Ethikrat (2011): Mensch-Tier-Mischwesen in der Forschung. Eigenverlag, Berlin.

Deutscher Ethikrat (2015): Hirntod und Entscheidung zur Organspende. Eigenverlag, Berlin.

Dickert, T. (1991): Naturwissenschaften und Forschungsfreiheit. Duncker \& Humblot, Berlin.

Doerig, A. et al. (2019): The unfolding argument: Why IIT and other causal structure theories cannot explain consciousness. In: Consciousness and Cognition 72: 49-59.

Dreier, H. (2013): Kommentierung zu GG Art. 1 Abs. 1. In: Dreier, H. (Hrsg.): Grundgesetz-Kommentar. 3. Auflage. Mohr Siebeck, Tübingen.

Ehrlich, S. (2000): Gewinnabschöpfung des Patienten bei kommerzieller Nutzung von Körpersubstanzen durch den Arzt? Peter Lang, Frankfurt am Main.

Faltus, T. (2021): Organoide, Assembloide, Gastruloide, SHEEFs \& Organ-on-Chip. In: MedR 39: 125-134. Farahany, N. et al. (2018): The ethics of experimenting with human brain tissue. In: Nature 556: 429432.

Fessl, S. (2019): Is it ethical to grow a brain in a petri dish? In: JSTOR Daily, Online-Publikation 11.12.2019. Unter: https://daily.jstor.org/is-it-ethical-to-grow-a-brain-in-a-petri-dish/ [21.01.2021]. 
Fink, S. (2005): Einwilligung und vertragliche Regelungen zur Entnahme von Körpersubstanzen, deren Aufbewahrung und Verwendung in Biobanken. Jur. Diss., Mannheim.

Fröhlich, A. (2012): Die Kommerzialisierung von menschlichem Gewebe. Lit, Münster.

Gassner, U. M./Opper, J. (2020): Zur Zulässigkeit therapeutischen Klonens mittels Zellkerntransfer. In: Opper, J. et al. (Hrsg.): Chancen und Risiken der Stammzellforschung. Berliner WissenschaftsVerlag, Berlin: 255-278.

Gerke, S. (2020): Die klinische Translation von hiPS-Zellen in Deutschland. In: Gerke, S. et al. (Hrsg.): Die klinische Anwendung von humanen induzierten pluripotenten Stammzellen. Springer, Berlin: 243-327.

Gogol, A. (2018): A human brain model in a petri dish? In: EurekAlert!, Online-Publikation 16.10.2018. Unter: https://www.eurekalert.org/pub_releases/2018-10/cwru-ahb101618.php [21.01.2021].

Goodall, R. (2020): A lab-grown brain: a mind of its own? Online-Publikation 10.11.2020. Unter: https://theboar.org/2020/11/a-lab-grown-brain-a-mind-of-its-own/ [15.03.2021].

Günther, H.-L. (2014): Kommentierung zu § 6. In: Günther, H.-L. et al. (Hrsg.): Embryonenschutzgesetz. 2. Auflage. Kohlhammer, Stuttgart.

Häberle, P. (2020): Kommentierung zu § 17 TPG. In: Erbs, G./Kohlhaas, M. (Hrsg.): Strafrechtliche Nebengesetze. Werkstand: 233, EL. Beck, München.

Halasz, C. (2004): Das Recht auf biomaterielle Selbstbestimmung. Springer, Berlin.

Harder, M. (2020): Herausforderungen innovativer Gewebemedizin aus unternehmerischer Sicht. In: Gerke, S. et al. (Hrsg.): Die klinische Anwendung von humanen induzierten pluripotenten Stammzellen. Springer, Berlin: 157-178.

Heselhaus, S. (2017): Kommentierung zu GRC Art. 3. In: Pechstein, M. et al. (Hrsg.): Frankfurter Kommentar. Mohr Siebeck, Tübingen.

Hoeren, T. (2019): Datenbesitz statt Dateneigentum. In: MMR 22: 5-8.

Hostiuc, S. et al. (2019): The moral status of cerebral organoids. In: Regenerative Therapy 10: 118-120. Hufen, F. (2001): Präimplantationsdiagnostik aus verfassungsrechtlicher Sicht. In: Medizinrecht 19: 440-451.

Hufen, F. (2017): Wissenschaft zwischen Freiheit und Kontrolle. In: NVwZ 36: 1265-1268.

Hurlbut, J. B. et al. (2017): Revisiting the Warnock rule. In: Nature Biotechnology 35(11): 1029-1042. DOI: $10.1038 /$ nbt.4015.

Hyun, I. et al. (2016) Revisit the 14-day rule. In: Nature 533: 169-171.

Hyun, I. et al. (2020): Ethical issues related to brain organoid research. In: Brain Research 1732: 146653. Hyun, I. et al. (2021): Human embryo researchbeyond the primitive streak. In: Sciene 371(6533): $998-$ 1000.

IAG Gentechnologiebericht (2020): Kernaussagen und Handlungsempfehlungen zu Organoiden. In: Bartfeld, S. et al. (Hrsg.): Organoide. Ihre Bedeutung für Forschung, Medizin und Gesellschaft. Nomos, Baden-Baden: 13-28.

Iltis, A. S. et al. (2019): Human embryo research beyond Day 14: Ethical questions and considerations. Unter: https://www.bakerinstitute.org/media/files/files/20b9e242/chb-pub-greenwallethics-021219.pdf [15.03.2021]. 
Jácomo, A. (2020): The promises of brain organoids in the context of bioethical redefinition. Embryo status, consent and animal research. In: EIDON 54:3-10.

Jarass, H. (2021a): Einleitung. In: Jarass, H. (Hrsg.): Charta der Grunderechte der EU. 4. Auflage. Beck, München.

Jarass, H. (2021b) Kommentierung zu GRC Art. 3. In: Jarass, H. (Hrsg.): Charta der Grunderechte der EU. 4. Auflage. Beck, München.

Kaulen, H. (2018): Braucht dieses Hirn einen Vormund? In: Frankfurter Allgemeine Zeitung, OnlinePublikation 25.05.2018. Unter: https://www.faz.net/-gx3-9ado5 [21.01.2021].

Kirk, R. (2009): Zombies. In: Zalta, E. N. (Hrsg.): Stanford Encyclopedia of Philosophy. Metphysics Research Lab, Stanford.

Koch, N. (2013): Das Biobankgeheimnis, Schutz der Persönlichkeitsrechte in der biomedizinischen Forschung. Online-Publikation 08.04.2013. DOI: 10.25358/openscience-4218.

Koplin, J./Savulescu, J. (2019): Moral limits of brain organoid research. In: J. Law Med. Ethics 47: 760767.

Kranz, S. (2008): Biomedizinrecht in der EU. Dr. Kovac, Hamburg.

Kurlemann, R. (2013): Neues Mini-Gehirn weckt Frankenstein-Fantasien. In: WirtschaftsWoche, Online-Publikation 29.08.2013. Unter: https://www.wiwo.de/technologie/forschung/stammzellenforschung-neues-mini-gehirn-weckt-frankenstein-fantasien/8712192.html [21.01.2021].

Kuroczik, J. (2018): Herr, wirf Hirn herunter. In: Frankfurter Allgemeine Zeitung, Online-Publikation 08.05.2018. Unter: https://www.faz.net/aktuell/wissen/medizin-ernaehrung/wie-weit-darf-dieforschung-mit-labor-gehirnen-gehen-15575367.html [21.01.2021].

Lange, M. (2019): „Mini-Gehirne“ aus Stammzellen: Was denkt ein Organoid in der Petrischale? In: Deutschlandfunk, Online-Publikation 01.01.2019. Unter: https://www.deutschlandfunk.de/minigehirne-aus-stammzellen-was-denkt-ein-organoid-in-der.740.de.html?dram:article_id=436772 [21.01.2021].

Lavazza, A. (2020): Human cerebral organoids and consciousness: a doubleedged sword. In: Monash Bioethics Review 38: 105-128.

Lavazza, A. (2021): Potential ethical problems with human cerebral organoids: Consciousness and moral status of future brains in a dish. In: Brain Research, Online-Publikation 01.01.2021. DOI: 10.1016/j.brainres.2020.147146.

Lavazza, A./Massimini, M. (2018): Cerebral organoids: ethical issues and consciousness assessment. In: J Med Ethics 44: 606-610.

Lavazza, A./Pizzetti, F. (2020): Human cerebral organoids as a new legal and ethical challenge. In: Journal of Law and the Bioscience, Online-Publikation 09.06.2020. DOI: 10.1093/jlb/lsaa005.

Loike, J. D. (2018): Opinion: Should human-animal chimeras be granted „personhood“? In: The Scientist, Online-Publikation 23.05.2018. Unter: https://www.the-scientist.com/news-opinion/opinionshould-human-animal-chimeras-be-granted-personhood-36664 [21.01.2021].

Marton, R./Pasca, S. (2019): Organoid and assembloid technologies for investigating cellular crosstalk in human brain development and disease. In: Trends Cell Biol 30(2): 133-143. DOI: 10.1016/j.tcb. 2019.11.004.

Matthews, K. R. W./Moralí, D. (2020): National human embryo and embryoid research policies: a survey of 22 top research-intensive countries. In: Regenerative Medicine 15(7): 1905-1917. 
Matthews, K. R. W. et al. (2021) Rethinking human embryo research policies. In: Hastings Cent Rep. 51(1): 47-51. DOI: 10.1002/hast.1215.

McCully, S. (2021): The time has come to extend the 14-day Limit. In: Med Ethics 0:1-5. DOI:10.1136/ medethics-2020-106406.

Mühlböck, L./Taupitz, J. (2021): Haftung für Schäden durch KI in der Medizin. In: AcP 221: 179-218.

Müller-Jung, J. (2013): „Zerebrale Organoide“ Was macht man mit so wenig Hirn? In: Frankfurter Allgemeine Zeitung, Online-Publikation 28.08.2013. Unter: https://www.faz.net/-gx5-7h03o [15.03.2021].

Müller-Terpitz, R. (2007): Der Schutz des pränatalen Lebens. Mohr Siebeck, Tübingen.

Munsie, M. et al. (2017): Ethical issues in human organoid and gastruloid research. In: Development 144: 942-945.

National Academies of Sciences, Engineering, Medicine (2021): The emerging field of human neural organoids, transplants, and chimeras: science, ethics, and governance. The National Academies Press, Washington, DC.

Ooi, L. et al. (2020): If human brain organoids are the answer to understanding dementia, what are the questions? In: The Neuroscientist 26(5-6): 438-454.

Parsch, S. (2019a): Hirn aus dem Labor. In: Süddeutsche Zeitung, Online-Publikation 29.08.2019. Unter: https://www.sueddeutsche.de/wissen/gehirn-labor-mini-brain-organoid-1.4580139 [21.01.2021].

Parsch, S. (2019b): Forscher züchten Mini-Gehirne im Labor. In: Der Spiegel, Online-Publikation 30.08.2019. Unter: https://www.spiegel.de/wissenschaft/mensch/forscher-zuechten-mini-gehirne-im-labor-a-1284395.html [21.01.2021].

Radau, W. C (2006): Die Biomedizinkonvention des Europarates. Springer, Berlin.

Reardon, S. (2020): Can lab-grown brains become conscious? In: Nature 586: 658-661.

Roidis-Schnorrenberg, H.-E. (2016): Das Verbot der Kommerzialisierung des menschlichen Körpers und seiner Teile. Verlag Universität Mannheim Service und Marketing, Mannheim.

Roth, C. (2009): Eigentum an Körperteilen. Springer, Berlin.

Sass, H.-M. (1989): Hirntod und Hirnleben. In: Sass, H.-M. (Hrsg.): Medizin und Ethik. Reclam, Stuttgart: $160-191$.

Sawai, T. et al. (2019): The ethics of cerebral organoid research: Being conscious of consciousness. In: Stem Cell Reports 13: 440-447.

Schicktanz, S. (2020): Sind menschliche zerebrale Organoide moralisch schützenswert? In: Bartfeld, S. et al. (Hrsg.): Organoide. Ihre Bedeutung für Forschung, Medizin und Gesellschaft. Nomos, Baden-Baden: 190-211.

Schnorrenberg, H.-E. (2010): Zur Kommerzialisierung menschlicher Körpersubstanzen: Verstößt die Vereinbarung der Zahlung eines Entgelt an den Substanzspender gegen die Menschenwürde? In: Potthast, T. et al. (Hrsg.): Wem gehört der menschliche Körper? Mentis, Paderborn: 223-242.

Scholz, K./Middel, C.-D. (2018): Kommentierung zu § 17 TPG. In: Spickhoff, A. (Hrsg.): Medizinrecht. 3. Auflage. Beck, München. 
Schreiber, M. (2019): Die medizinische Forschung mit abgetrennten Körpersubstanzen Minderjähriger. Lit, Münster.

Schröder, M./Taupitz, J. (1991): Menschliches Blut: verwendbar nach Belieben des Arztes? Enke, Stuttgart.

Schwarzburg, K. (2012): Die Menschenwürde im Recht der Europäischen Union. Nomos, Baden-Baden. Sharma, A. et al. (2020): Scientific and ethical uncertainties in brain organoid research. In: The American Journal of Bioethics 21(1): 48-51.

Shepherd, J. (2018): Counsciousness and moral status. Routledge, London.

Shou, Y. et al. (2020): The application of brain organoids: From neuronal development to neurological diseases. In: Front. Cell Dev. Biol., Online-Publikation 22.10.2020. DOI: 10.3389/fcell.2020.579659.

Sidhaye, J./Knoblich, J. A. (2021): Brain organoids: an ensemble of bioassays to investigate human neurodevelopment and disease. In: Cell Death \& Differentiation 28: 52-67.

Singer, W. (2019): A naturalistic approach to the hard problem of consciousness. In: Front. Syst. Neurosci., Online-Publikation 25.10.2019. DOI: 10.3389/fnsys.2019.00058.

Tag, B. (2017): Kommentierung zu § 18 TPG. In: Münchener Kommentar zum StGB. 3. Auflage. Beck, München.

Tanaka, Y./Park, I.-H. (2020): Hirnorganoide vom gesamten Gehirn oder von spezifischen Hirnregionen und deren mögliche Anwendungen. In: Bartfeld, S. et al. (Hrsg.): Organoide. Ihre Bedeutung für Forschung, Medizin und Gesellschaft. Nomos, Baden-Baden: 116-125.

Taupitz, J. (1991): Wem gebührt der Schatz im menschlichen Körper? - Zur Beteiligung des Patienten an der kommerziellen Nutzung seiner Körpersubstanzen. In: Archiv für die civilistische Praxis 191: 201-246.

Taupitz, J. (1996): Das Recht im Tod: Freie Verfügbarkeit der Leiche? - Rechtliche und ethische Probleme der Nutzung des Körpers Verstorbener. Humanitas, Dortmund.

Taupitz, J. (2000): Forschung mit menschlichen Zellen in Österreich. In: Juristische Blätter 122: 152161.

Taupitz, J. (2001): Der rechtliche Rahmen des Klonens zu therapeutischen Zwecken. In: Neue Juristische Wochenschrift 54: 3433-3440.

Taupitz, J. (2002): Biomedizinische Forschung zwischen Freiheit und Verantwortung. Springer, Berlin.

Taupitz, J. (2014a): Kommentierung zu § 8 ESchG. In: Günther, H.-L. et al. (Hrsg.): Embryonenschutzgesetz. 2. Auflage. Kohlhammer, Stuttgart.

Taupitz, J. (2014b): Juristische Grundlagen. In: Günther, H.-L. et al. (Hrsg.): Embryonenschutzgesetz. 2. Auflage. Kohlhammer, Stuttgart. B. I-III.

Taupitz, J. (2017): Verkauf von Restblut an die Medizinprodukteindustrie: nur mit Einwilligung des Patienten? In: Medizinrecht 35: 353-361.

Taupitz, J. (2020a): Organoide. In: Medizinrecht 38: 805-813.

Taupitz, J. (2020b): Organoide: Die deutsche Rechtslage. In: Bartfeld, S. et al. (Hrsg.): Organoide. Ihre Bedeutung für Forschung, Medizin und Gesellschaft. Nomos, Baden-Baden: 212-236.

Taupitz, J. (2020c): Biobanken: Forschungsprivilegien im Datenschutzrecht. In: Katzenmeier, C. (Hrsg.): Festschrift für Dieter Hart. Springer, Berlin: 603-625.

Taupitz, J./Weschka, M. (Hrsg.) (2009): CHIMBRIDS - chimeras and hybrids in comparative European and international research. Springer, Berlin.

Teubner, G. (2018): Digitale Rechtssubjekte? In: Archiv für die civilistische Praxis 218: 155-295. 
Trujillo, C. et al. (2019): Complex oscillatory waves emerging from cortical organoids model early human brain network development. In: Stem Cell 25(4): 558-569.

Viciano, A. (2020): Das Mini-Gehirn wird durchleuchtet. In: Süddeutsche Zeitung, Online-Publikation 20.10.2020. Unter: https://www.sueddeutsche.de/wissen/hirnforschung-genetik-genscherecrispr-cas9-organoide-1.5098193 [21.01.2021].

Vossenkuhl, C. (2013): Der Schutz genetischer Daten. Springer, Berlin.

Weiler, N. (2020): Not ,brains in the dish': Cerebral organoids flunk comparison to developing nervous system. In: Research, Online-Publikation 29.01.2020. Unter: https://www.ucsf.edu/ news/2020/01/416526/not-brains-dish-cerebral-organoids-flunk-comparison-developingnervous-system [21.01.2021].

Yeager, A. (2018): As brain organoids mature, ethical questions arise. In: The Scientist, Online-Publikation 01.08.2018. Unter: https://www.the-scientist.com/features/brain-organoids-mature--raiseethical-questions-64533 [21.01.2021].

Zech, E. (2007): Gewebebanken für Therapie und Forschung: Rechtliche Grundlagen und Grenzen. Cuvillier, Göttingen.

Zech, H. (2020): Entscheidungen digitaler autonomer Systeme: Empfehlen sich Regelungen zu Verantwortung und Haftung?. Gutachten A zum 73. Dt. Juristentag. Beck, München.

Ziebarth, W. (2018): Kommentierung zu Art. 4 DSGVO. In: Sydow, G. (Hrsg.): Europäische Datenschutzgrundverordnung. 2. Auflage. Nomos, Baden-Baden. 